\title{
Políticas educacionais na Amazônia: reflexão acerca das políticas para o ensino médio da escola pública na região tocantina e Vale do Acará/PA
}

\section{Educational Policies in the Amazon: Reflection on policies for public high school education in the region of Tocantins and Vale do Acará/PA}

\author{
Fahid da Costa Kemil ${ }^{1 *}$, Afonso Welliton de Sousa Nascimento $1^{2}$, Alexandre Augusto \\ Cals e Souza $2^{1}$
}

\begin{abstract}
RESUMO
O artigo busca responder como as políticas públicas de educação têm refletido sobre o Ensino Médio (EM) no município de Abaetetuba/PA? Partindo da discussão de Políticas Públicas de Educação, verificando a Lei de Diretrizes e Bases, o Plano Nacional de Educação e o Plano Estadual da Educação. Fazendo a relação com o EM a partir da bibliografia utilizada e de entrevistas realizadas com oito pessoas, sendo quadro delas professores e quatro alunos do Ensino Médio de duas escolas públicas. O objetivo desde estudo consiste em identificar o reflexo das políticas públicas educacionais, mais especificamente do EM em escolas públicas estaduais. A partir das entrevistas realizadas foi possível identificar que os alunos vêm tendo dificuldades em relacionar os conteúdos abordados em sala de aula com a realidade em que vivem. Na visão dos professores são identificados três perfis de escolas no município de Abaetetuba, as que buscam apenas aprovação em vestibulares, as que visam, além disso, o trato de conhecimentos culturais e as que apenas se preocupam em transmitir conteúdos em sua maioria descontextualizados.
\end{abstract}

Palavras-chave: Educação na Amazônia; Ensino Médio; Políticas Públicas Educacionais.

\begin{abstract}
The article seeks to answer how public education policies have reflected on High School (EM) in the city of Abaetetuba/PA? Starting from the discussion of Public Education Policies, verifying the Law of Directives and Bases, the National Education Plan and the State Education Plan. Making the relationship with the EM from the bibliography used and from interviews with eight people, including teachers and four high school students from two public schools. The objective of this study is to identify the reflection of public educational policies, more specifically of EM in state public schools. From the interviews carried out, it was possible to identify that students have been having difficulties in relating the contents covered in the classroom with the reality in which they live. In the view of the teachers, three profiles of schools in the municipality of Abaetetuba are identified, those that seek only approval in entrance exams, those that aim, in addition, to deal with cultural knowledge and those that are only concerned with transmitting mostly decontextualized content.
\end{abstract}

\footnotetext{
${ }^{1}$ Universidade Federal do Pará- UFPA

*E-mail: alexandre@ufpa.br
} 


\section{INTRODUÇÃO}

No Brasil é possível verificar diferenciações no ensino de acordo com o grupo social, as escolas que atendem os setores populares pelas condições infraestruturais oferecidas, nem sempre conseguem manter a qualidade desejada. A educação é direito de todos, mas vem sendo tratada como privilégio de alguns, segundo Simões (2011), ocorre a distribuição desigual do capital simbólico da escola. O que justifica o interesse de maior compreensão sobre a temática estudada. Ela tende a se expandir com funções mais voltadas às formas tradicionais de regulação. O capitalismo precisa da escola por razões ideológicas e econômicas, mas se recusa a mudar a função social dessa instituição.

A pesquisa busca responder como as políticas públicas de educação têm refletido sobre o Ensino Médio no município de Abaetetuba/PA? Partindo da discussão de Políticas Públicas de Educação e Ensino Médio, verificando a Lei de Diretrizes e Bases, o Plano Nacional de Educação e o Plano Estadual da Educação. Fazendo a relação com o Ensino Médio a partir da bibliografia utilizada e de entrevistas realizadas com oito pessoas, sendo quatro professores(as) e quatro alunos(as) do Ensino Médio de duas escolas públicas de Abaetetuba. Onde quatro dos sujeitos são de uma escola e as outras quatro da segunda escola, tanto docentes quanto discentes.

O objetivo deste estudo consiste em identificar a relação das políticas públicas educacionais, mais especificamente com o Ensino Médio em escolas públicas no município de Abaetetuba, a partir de uma revisão bibliográfica e de entrevistas semiestruturadas com os informantes da pesquisa. Sendo relevante no sentido de outros olhares, acerca da temática além de fomentar o debate sobre o assunto.

A proposta, para Simões (2011) é de unidade entre os aspectos manuais e intelectuais no Ensino Médio, envolvendo o exercício das mãos e da mente, não havendo a limitação da escola aos interesses imediatos, utilitários e pragmáticos, mas, com proposições a refletir, pensar e compreender as determinações da vida social e produtiva, articulando o trabalho, a ciência e a cultura, visando à emancipação humana.

\section{BREVE REFLEXÃO SOBRE ESTADO E POLÍTICAS PÚBLICAS}

É relevante considerarmos a diferenciação entre as nomenclaturas Estado e Governo. Segundo Hofling (2001), o Estado é um conjunto de instituições permanentes 
(órgão legislativos, tribunais, exército e outras) que possibilitam a ação do governo. Esse último é o conjunto de programas e projetos que parte da sociedade, propondo para a sociedade como um todo, caracterizando-se como a orientação política de um dado governo que assume e desempenha as funções de Estado num determinado período.

Os neoliberais não defendem a responsabilidade do Estado em relação ao oferecimento de educação pública a todo cidadão, de forma padronizada e universal, Hofling (2001). Segundo a autora, a centralização na escolaridade, trouxe unidades maiores, reduzindo a capacidade dos consumidores de escolher e aumentando o poder dos produtores. As teorias neoliberais propõem que o Estado transfira suas responsabilidades para o setor privado, então as famílias teriam o direito de livre escolha sobre a educação desejada para seus filhos, estimulando a competição entre os serviços oferecidos no mercado. Portanto, a educação como produto mercadológico

Tem sido mais comum no Brasil a reivindicação de iniciativas governamentais na área da educação, em especial para que sejam desenvolvidas como políticas públicas de Estado. De acordo com Simões (2011), o conceito mais adequado de política pública, propõe a ideia de Estado e não de governo. Havendo conceitos polissêmicos para o termo "política pública", onde este engloba o sentido de uma ação com os objetivos e meios para sua realização.

Ao se falar em políticas públicas, era pensado em uma intervenção do Estado numa situação social problemática. Entretanto, como afirma Simões (2011), toda política pública é uma intervenção estatal, havendo a necessidade de incorporar a esse conceito o que resulta da interação e do conflito entre a concepção de Estado e as necessidades exigidas pela sociedade civil.

São várias as fases das políticas públicas educacionais, segundo Simões (2011), a identificação da questão, formulação, autorização, implementação, monitoramento e avaliação. Todas essas fases envolvem diversos personagens. Tendo quatro diferentes ângulos e elementos de observação das políticas públicas, como coloca o autor: teoria, práticas e resultados; atores interesses e regras; custos, suporte e financiamentos; saberes, valores e linguagens. Componentes que refletem efetivamente nas políticas educacionais em especial nas voltadas ao Ensino Médio.

\section{POLÍTICAS EDUCACIONAIS E ENSINO MÉDIO}


O Ensino Médio faz parte da educação básica, situado entre o nível fundamental e o superior. Essa denominação sofreu muitas variações ao longo do tempo e das políticas públicas da educação brasileira. Segundo Lima et al (2009), na lei 4.024/61, a denominação era Educação de Grau Médio ou Ensino Médio, dividida em dois ciclos, Ginasial e Colegial. O ginásio tinha suas duas primeiras séries com oito disciplinas, dessas, uma ou duas eram optativas. A terceira série era embasada em um currículo pautado em aspectos históricos, linguísticos e literários. Já o colegial tinha um currículo mais diverso, objetivando a preparação para cursos superiores, tendo de quatro a seis disciplinas.

Com a reforma de 1971, sob a Lei 5.692, as escolas passaram a priorizar a formação técnica, o Ensino Médio recebeu o nome de " $2^{\circ}$ Grau", mantendo-se com essa estrutura até a publicação da Lei de Diretrizes e Bases (LDB) n 9.394/96, como afirma Lima et al (2009). Segundo os autores, um fato curioso dessa formação foi o não atendimento aos objetivos propostos, uma vez que não foi desenvolvido o gosto pela cultura e também não houve a formação de técnicos capacitados para o mundo do trabalho.

A partir da publicação da LDB, esse nível de ensino passou a ser chamado de Ensino Médio. Em seu Artigo 35 o Ensino Médio é caracterizado como a etapa final da educação básica, tendo a duração mínima de três anos e as finalidades de preparar o educando para prosseguir os estudos em nível técnico ou superior, além de objetivar a preparação básica para o trabalho e para a cidadania, formação ética, desenvolvimento da autonomia intelectual, pensamento crítico, o entendimento dos fundamentos científicotecnológicos dos processos produtivos; compondo um currículo que aborde a educação tecnológica básica, a compreensão do significado da ciência, das letras e das artes, assim como os conhecimentos acerca do processo histórico, das transformações sociais e culturais, tendo a língua portuguesa como instrumento de comunicação. Além disso, o Ensino Médio também pode formar o educando para o exercício de profissões técnicas.

O Ensino Médio no Brasil tem sido considerado um nível de difícil enfrentamento, segundo Simões (2011), devido à sua concepção, estrutura, forma de organização, mediação e à particularidade de atender à juventude. Ele vem com duas propostas, preparar para a continuidade dos estudos e para o mundo do trabalho, no projeto capitalista de sociedade, dentro de determinadas ralações sociais. 
Na contramão a essa concepção, o conceito de politecnia, pensado por Gramsci (2006) vem agregar a escola ao trabalho, propondo fundamentos científicos de diferentes técnicas relacionadas ao trabalho moderno, à união entre instrução intelectual e trabalho produtivo. Para o melhor desenvolvimento das questões culturais e educacionais, é necessária a superação dessa proposta dual de educação, na visão de Simões (2011). Não basta apenas reivindicar mais educação para os trabalhadores, mas a busca se estende a um tipo de escola novo, com perspectivas de transformação social.

Se faz necessária a definição da identidade do Ensino Médio, sendo esse, a etapa final da educação básica, tendo no trabalho um princípio educativo e não uma adaptação à organização produtiva. Para Simões (2011) as dimensões constituintes dessa identidade devem ser: trabalho, ciência, tecnologia e cultura. Pautado na universalização de um Ensino Médio de qualidade de cultura geral e ampla, articulando conhecimentos e saberes da ciência, tecnologia, cultura e do trabalho.

\section{LEGISLAÇÃO NACIONAL E O ENSINO MÉDIO}

Políticas Públicas são entendidas como o Estado implantando um projeto de governo, na visão de Hofling (2001), por meio de programas e ações voltadas para setores específicos da sociedade. Para a autora a educação é tida como uma política pública social, de corte social, de responsabilidade do Estado, a qual não é pensada apenas por seus organismos.

A partir de 1985, com a redemocratização da sociedade brasileira, surgiu um movimento que revisou suas instituições e leis, resultando na Assembléia Nacional Constituinte. A Constituição Federal, de 1988, acarretou em mudanças nos direitos civis como a educação, exigindo reformas. Então, um tempo de debate e resistência na elaboração da Carta Magna, de certa forma, participativa, com um certo grau de envolvimento pela sociedade organizada. Nesse contexto, a ideia de uma Lei de Diretrizes e Bases da Educação Nacional (LDB) com princípios populares, seria a tônica inicial. Com ela, viriam as propostas de politecnia no Ensino Médio. Entretanto, a ala conservadora do Congresso Nacional conseguiu atrasar a aprovação dessa lei e quando tiveram a presença de um eixo político favorável, veio a ideia de outro projeto, o qual valorizava muito mais a educação profissional, na perspectiva neoliberal, passando a dominar o Estado a partir de 1990. 
A LDB (Lei n ${ }^{\circ}$ 9.394, de 1996) estabelece a identidade do Ensino Médio como uma etapa de consolidação da educação básica, aprimorando o educando como ser humano, retrata a continuidade e aprofundamento dos conhecimentos adquiridos no ensino fundamental, oferecendo a preparação básica para o trabalho e a cidadania. Assim, de acordo com Simões (2011) o governo centrou sua ação na integração do Ensino Médio com a educação profissional, sem propor um ensino não profissionalizante, de interesse dos trabalhadores e da juventude em geral.

A LDB define e regulariza o sistema de educação brasileiro, com base nos princípios presentes na Constituição Federal de 1988. Segundo Lima et al (2009), a primeira LDB foi criada em 1961, seguida por uma versão em 1971, que vigorou até o estabelecimento da mais recente, em 1996. Essa lei é composta por diretrizes, indicativa e não resolutiva das questões educacionais. Essas diretrizes fazem relação com o artigo 210 da Constituição Federal de 1988. A Resolução número 2, de abril de 1998, da Câmara de Educação Básica, apresenta as Diretrizes Curriculares Nacionais (DCN), como diretrizes de base descritas pela Carta Magna Brasileira, sendo essa, matéria-prima da Lei de Diretrizes e Bases da Educação Nacional. Segundo Lima et al (2009), para o funcionamento das redes escolares, é necessária a união das ações do texto constitucional e do contexto da LDB. A partir dessa realidade surgem a política e os planejamentos educacionais no intuito de estabelecer um funcionamento independente e harmônico.

O Artigo 36 da LDB trata as diretrizes do currículo do Ensino Médio destacando a Educação Tecnológica Básica, a compreensão do significado da ciência, das letras e das artes, o processo histórico de transformação da sociedade e da cultura e tendo a língua portuguesa como instrumento de comunicação, acesso ao conhecimento e exercício da cidadania. Esse artigo também propõe o uso de metodologias de ensino e avaliação que estimulem a iniciativa dos estudantes, além da inclusão de uma língua estrangeira moderna como disciplina obrigatória escolhida pela escola e uma segunda, em caráter optativo. Essas metodologias e avaliações devem proporcionar ao aluno, no final do curso, domínio dos princípios científicos e tecnológicos da produção moderna do conhecimento. Conhecimentos sobre as formas contemporâneas de linguagem, saberes sociológicos e filosóficos necessários ao exercício da cidadania:

$\S 1^{\circ}$ Os conteúdos, as metodologias e as formas de avaliação serão organizados de tal forma que ao final do ensino médio o educando demonstre: 
I - domínio dos princípios científicos e tecnológicos que presidem a produção moderna;

II - conhecimento das formas contemporâneas de linguagem;

III - domínio dos conhecimentos de Filosofia e de Sociologia necessários

ao exercício da cidadania.( LDB, Lei $N^{\circ}$ 9.394/1996.)

A Lei 13.005 de 25 de junho de 2014 aprova o Plano Nacional de Educação (PNE 2014), o qual descreve diretrizes e metas para a educação no Brasil, estabelecendo o prazo de dez anos para a sua realização, ou seja, são metas para serem realizadas em até dez anos e assim vai ocorrendo sua atualização. Entre as principais metas podemos citar a melhoria da qualidade do ensino e a erradicação no analfabetismo. Sobre o Ensino Médio é possível observar na terceira meta do referido Plano a intenção em universalizar o atendimento escolar, elevando a taxa líquida de matrículas no Ensino Médio:

Meta 3: universalizar, até 2016, o atendimento escolar para toda a população de 15 (quinze) a 17 (dezessete) anos e elevar, até o final do período de vigência deste PNE, a taxa líquida de matrículas no ensino médio para $85 \%$ (oitenta e cinco por cento). (PNE, 2014).

A meta 3 do Plano Nacional trata sobre a universalização, até 2016, do atendimento escolar para a população com idade entre 15 e 17 anos, visando elevar até 2024, a taxa líquida de matrículas no Ensino Médio para 85\%. Para a concretização de tal meta existe a necessidade de uma política clara com o intuito de garantir o acesso e permanência à educação com qualidade. Atualmente, ainda não houve a universalização do atendimento escolar, o caminho é mais longo e complexo devido às enormes disputas que marcam a concepção de juventude, as diferentes realidades em que se encontram os jovens, suas expectativas e as possibilidades de oferta de oportunidades educacionais pelo poder público. Todos esses aspectos interferem no acesso, assim como na adequação série-idade dos jovens, sendo desafios para os próximos anos. As medidas adotadas até então pelo governo tem sido insuficientes diante das dificuldades encontradas no eixo do acesso e permanência à educação com qualidade no Ensino Médio brasileiro.

Em sua sétima meta é tratada como proposta melhorar a qualidade da educação básica, visando elevar os níveis do IDEB: "Meta 7: fomentar a qualidade da educação básica em todas as etapas e modalidades, com melhoria do fluxo escolar e da aprendizagem" (PNE, 2014). Já em sua oitava meta a intenção é de elevar a escolaridade média da população com idade entre 18 e 29 anos, em especial nas regiões de menores índices de escolaridade, igualando a escolaridade média entre as populações: 
Meta 8: elevar a escolaridade média da população de 18 (dezoito) a 29 (vinte e nove) anos, de modo a alcançar, no mínimo, 12 (doze) anos de estudo no último ano de vigência deste Plano, para as populações do campo, da região de menor escolaridade no País e dos $25 \%$ (vinte e cinco por cento) mais pobres, e igualar a escolaridade média entre negros e não negros declarados à Fundação Instituto Brasileiro de Geografia e Estatística - IBGE. (PNE, 2014).

A meta 11 visa triplicar as matrículas da educação profissionalizante de nível médio, garantindo a qualidade de oferta. É uma meta importante, porém não estabelece prazos nem meios que permitam seu monitoramento e avaliação. Ao se falar em expansão profissional e técnica é preciso pensar a ação da rede pública, a manutenção do processo, a interiorização e democratização para que todos tenham esse direito garantido independente da localidade, condição social, atendimento especial e outros. Todos têm esse direito e ele deve ser garantido. Além disso, é perceptível a necessidade em ampliar os debates sobre as políticas e processos formativos presentes nesse processo.

Políticas voltadas para a educação e aqui, mais especificamente voltadas ao EM devem envolver debates com pesquisadores professores, gestores, redes e sistemas, pessoas inseridas nesse processo e nessa realidade, estudiosos da área. Existe a necessidade de envolver sua participação de forma democrática e transparente. Não é reduzindo o currículo que se resolve o problema, como afirma Dourado (2017), assim fazendo pode haver a negação do direito a múltiplas oportunidades formativas e à formação básica comum, reforçando a desigualdade no âmbito das desigualdades educacionais. Algumas das dificuldades já sinalizadas envolvem a falta de estrutura e recursos. Diversos municípios brasileiros apresentam apenas uma escola pública com oferta ao Ensino Médio, com turno triplo, além disso, vários professores não possuem formação na área em que lecionam. Esses são alguns dos fatores que inviabilizam, na maioria dos municípios a garantia do ensino, a oferta de educação integral e outros. Por não haver a estrutura necessária para a garantia da proposta.

Para a concretização das metas e a superação de algumas das dificuldades presentes no EM, é fundamental considerar a interdisciplinaridade, a inovação, a relação entre teoria e prática e currículos que organizem de forma equilibrada e diversificada os conteúdos, articulando-os em diferentes contextos. A política de EM precisa considerar as questões curriculares específicas, os aspectos voltados à infra estrutura, os objetivos, a profissionalização docente, assim como, as diversidades sociais. Dessa forma, existem grandes desafios para o cumprimento das metas até o prazo estabelecido, pois, muitos passos precisam ser dados ainda. 
As lutas sobre as políticas públicas, inclusive a defesa ao Plano Nacional de Educação, envolvem a organização e mobilização da sociedade civil na busca da superação da lógica histórico política brasileira, a qual é limitada nos aspectos estruturais, políticos, econômicos, culturais e pedagógicos, como afirma Dourado (2017). Durante a história da educação brasileira vem ocorrendo diversas disputas de projetos com distintas concepções sobre o papel do Estado e do planejamento, havendo diferentes visões políticas e pedagógicas refletindo em vários campos da educação, como no financiamento e nos processos de gestão. A partir da polarização entre os adeptos ao ensino público e os adeptos do ensino privado, o uso e a compreensão do fundo público tem sofrido argumentos éticos e políticos.

A falta de um sistema nacional de educação institucionalizado, a existência de políticas e planejamento descontinuados, a falta de cooperação entre a União, os estados, o Distrito Federal e os municípios, são fatores que dificultam os meios de acesso e garantia à educação. Levando a discussões tardias sobre a concretização de planos nacionais e/ou setoriais que, de acordo com Dourado (2017), estão em debate desde a década de 1930.

\section{A EDUCAÇÃo PARAENSE A PARTIR DO PLANO ESTAdUAL DE EDUCAÇÃO}

O Plano Estadual de Educação (PEE), desenvolvido no estado do Pará, tem vigência de dez anos, visa articular as políticas educacionais com as políticas sociais, em especial as culturais; considerar as necessidades específicas da população do campo e das comunidades indígena e quilombolas, garantir a equidade educacional e a diversidade cultural; possibilitar o atendimento das necessidades específicas na educação especial em todos os níveis, etapas e modalidades e fazer articulações interfederativas para a implementação de políticas educacionais. Em seu Artigo $1^{\circ}$ são esclarecidas suas estratégias:

I - articulação das políticas educacionais com as demais políticas sociais, particularmente as culturais;

II - consideração com as necessidades específicas das populações do campo e das comunidades indígenas e quilombolas, asseguradas a equidade educacional e a diversidade cultural; 
III - garantia do atendimento das necessidades específicas na educação especial, assegurado o sistema educacional inclusivo em todos os níveis, etapas e modalidades;

IV - promoção da articulação interfederativa na implementação das políticas educacionais. (PNE, Lei $\mathrm{N}^{\circ} 8.186$, de 23 de junho de 2015)

O PEE em seu Artigo $2^{\circ}$ trata sobre suas diretrizes, como é possível observar a seguir:

I - erradicação do analfabetismo;

II - universalização do atendimento escolar;

III - superação das desigualdades educacionais, com ênfase na promoção da cidadania e na erradicação de todas as formas de discriminação;

IV - melhoria da qualidade da educação;

V - formação para o trabalho e para a cidadania, com ênfase nos valores morais e éticos em que se fundamenta a sociedade;

VI - promoção do princípio da gestão democrática da educação pública; VII - promoção humanística, científica, cultural e tecnológica do Estado;

VIII - estabelecimento de meta de aplicação de recursos públicos em educação como proporção do Produto Interno Bruto - PIB, que assegure atendimento às necessidades de expansão, com padrão de qualidade e equidade;

IX - valorização dos profissionais da educação;

$X$ - promoção dos princípios do respeito aos direitos humanos, à diversidade e à sustentabilidade socioambiental.

Assim, o Plano Estadual de Educação é composto por metas e estratégias que visam sua realização e cumprimento no prazo de dez anos, uma década. Visando a oferta de ensino a todos com igualdade e qualidade, promovendo o respeito e o atendimento aos direitos da população. Tem vigência de dez anos, contados a partir de sua publicação, em junho de 2015. O Plano trata sobre dificuldades que são encontradas diariamente nos diversos municípios do estado do Pará. Porém muitas vezes a realidade parece estar em curso contrário às proposições legislativas, onde ainda é visível a desvalorização do profissional da educação e a falta de investimentos na área.

\section{REALIDADE EDUCACIONAL E O ENSINO MÉDIO}

Segundo a LDB, lei 9394/96 o Ensino Médio é um processo da educação básica para o exercício da cidadania, para o acesso às atividades produtivas e para o prosseguimento nos níveis mais elevados de estudos. Em seu Artigo 22 a LDB coloca que a educação básica tem como finalidade desenvolver o educando, garantindo a ele 
formação cidadã e meios para progredir no trabalho e prosseguir nos estudos. De acordo com Carmo (2013) sobre as vagas em universidades publicas os cursos de maior concorrência tem predominância de alunos provenientes do Ensino Médio em escolas particulares. Já os cursos menos concorridos, têm um número maior de alunos oriundos de escolas públicas. Em termos de aprovação escolar, também é verificado um índice maior de aproveitamento nas escolas particulares. E os percentuais de repetência e abandono tem sido maiores em escolas públicas. A evasão escolar, segundo Carmo (2013), é maior em escolas públicas. A carga horária em sala de aula também costuma ser maior em escolas particulares, comparadas às privadas. Embora haja certa similaridade de qualidade de ensino em ambas as redes.

Os mapas abaixo trazem alguns dados sobre a Educação Básica, mais especificamente o Ensino Médio no Brasil em 2014:

Mapa 1: Educação básica 2014

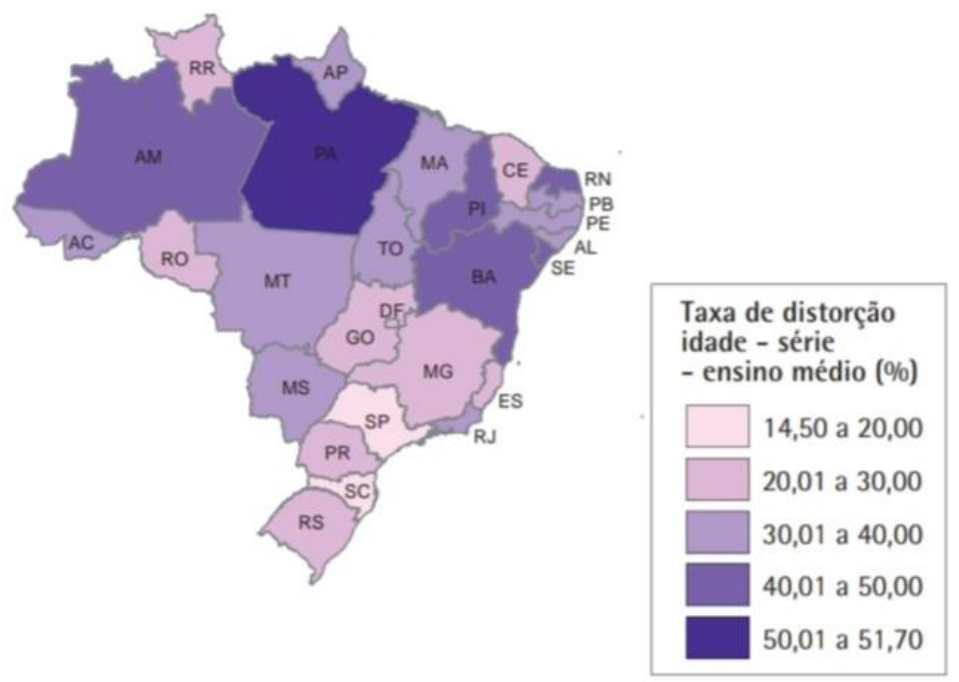

Fonte: IBGE, 2021

Mapa 2: Educação básica 2014 


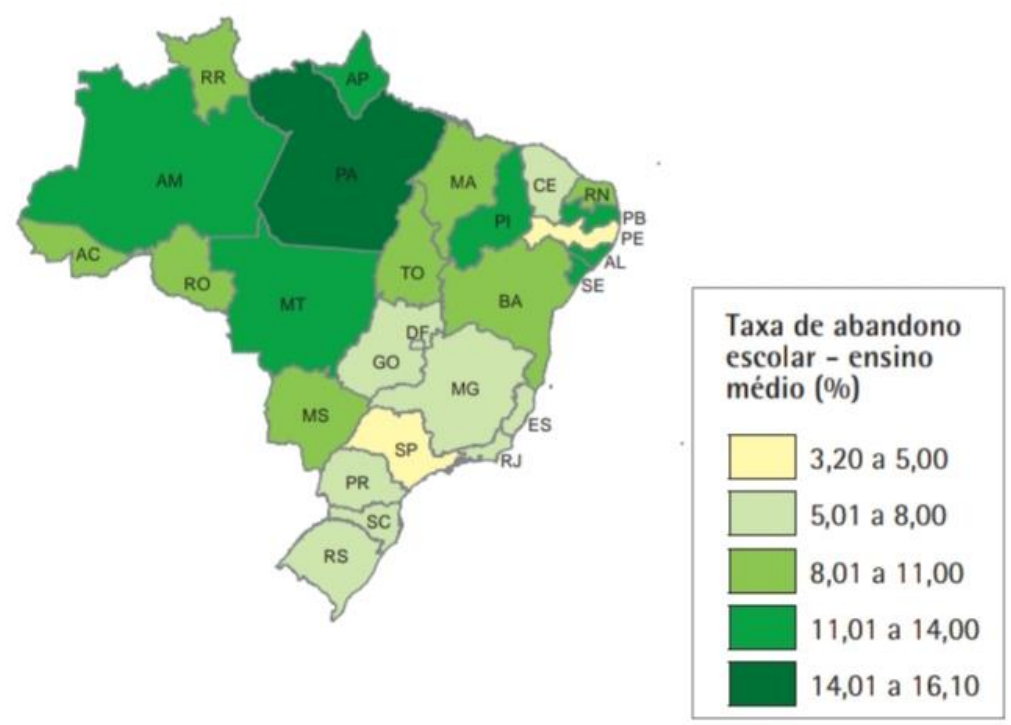

Fonte: IBGE, 2021.

A partir dos Mapas 1 e 2 é possível identificarmos a taxa de distorção idade-série no Ensino Médio, assim como a taxa de abandono escolar nesse nível de ensino. Onde as taxas de distorção idade-série variam de $14,50 \%$ a $51,70 \%$ entre os estados brasileiros. $\mathrm{O}$ estado do Pará se encontra com a maior taxa, de 50,01\% a 51,70\%. A taxa de abandono escolar varia de $3,20 \%$ a $16,10 \%$ entre os estados brasileiros, onde também o estado paraense está com a maior taxa, de $14,01 \%$ a $16,10 \%$.

Mapa 3: Educação Básica 2014. 


\section{População sem instrução}

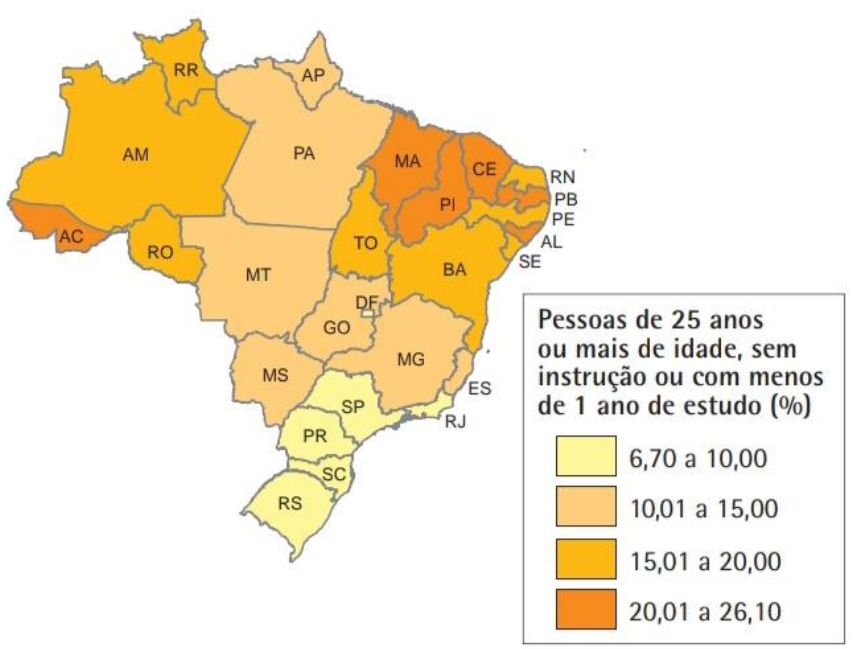

Fonte: IBGE, 2020.

O Mapa 3 traz uma análise sobre o quantitativo brasileiro da população sem instrução. Ao se falar sobre a população de 25 anos de idade ou mais, sem instrução ou com menos de um ano de estudo, o percentual varia de $6,70 \%$ a $26,10 \%$ entre os estados brasileiros. Sendo de $10,01 \%$ a $15 \%$ no estado do Pará.

Uma falha do sistema regular de ensino pode-se dizer que seja a descontextualização dos saberes e a dificuldade de contextualizá-los e trazê-los para a realidade do aluno. Segundo Carmo (2013) a partir das décadas de 1960 e 1970, com o elevado desenvolvimento da industrialização do país, a política educacional priorizou a capacitação de mão de obra mecanizada para a produção.

O problema da cobertura do Ensino Médio persiste segundo Melo e Duarte (2011) é o alto índice de jovens que estão fora da escola, especialmente aqueles com idade acima de 14 a 17 anos. Foram adotadas iniciativas supostamente voltadas para a melhoria do Ensino Médio, dentre as quais as autoras citam: a responsabilidade da oferta prioritária foi transferida para os estados, foi modificada a estrutura e relação com a educação profissional, foi introduzido o currículo por competências e a avaliação em larga escala, passando a ser usada como forma de ingresso no nível superior e outras. Entretanto, segundo as autoras, essas medidas não foram suficientes para a ampliação da cobertura nem para a melhoria da qualidade do ensino oferecido. 
Seria interessante que o Ensino Médio tivesse uma política específica que o conduza além da mera intervenção na formação, como afirma Pereira (2008), mas considere os direitos dos sujeitos enquanto cidadãos. No estado do Pará o desafio é a efetivação de políticas que visem além da inserção de jovens com idade entre 15 e 17 anos no Ensino Médio, mas também a sua permanência e continuação dos estudos, segundo Pereira (2008), por meio da criação de uma rede de escolas com a possibilidade de desenvolver um currículo que atenda às necessidades dos alunos.

\section{POLÍTICA EDUCACIONAL DO ENSINO MÉDIO REFLEXOS EM ESCOLAS PÚBLICAS NO MUNICÍPIO}

Para a melhor compreensão da situação atual do Ensino Médio no município de Abaetetuba, foram realizadas oito entrevistas com quatro alunos de duas escolas públicas e quatro professores sendo quatro de cada uma das escolas. Assim, foi possível identificar a relação entre as políticas públicas de educação para o Ensino Médio e a realidade atual nas respectivas escolas públicas que oferecem esse nível de ensino.

A partir das entrevistas realizadas com as professoras foi possível observar que algumas escolas de Abaetetuba têm foco na preparação para o vestibular, outras para o desenvolvimento cultural além da preparação para o vestibular e ainda há escolas que se preocupam apenas com a transmissão de conteúdos. Em resposta à primeira pergunta, sobre os objetivos demonstrados no Ensino Médio, pelas escolas e como eles se aplicam, na visão de uma das professoras entrevistadas: "O Ensino Médio em Abaetetuba vem mostrando hoje três perfis de escolas, as que visam a preparação para o vestibular, conhecimentos gerais e culturais além dessa preparação e as que buscam a mera transmissão de conteúdos" (PROFESSORA A). A segunda entrevistada mencionou como principais objetivos no Ensino Médio em Abaetetuba os mesmos pontos relatados pela primeira e acrescentou: “Atualmente trabalho em duas escolas públicas aqui no município, uma busca a preparação dos alunos para a aprovação em vestibulares, a outra busca o desenvolvimento dos conteúdos planejados" (PROFESSORA B). A entrevistada, assim como a anterior, fez um relato geral sobre o município, pois, ambas tem acesso a informações de várias escolas: "Na verdade em ambas as escolas que trabalho dificilmente conseguimos cumprir com o planejamento, as vezes chegamos ao final do ano sem termos estudado a metade do esperado [...]"(PROFESSORA A). Ainda, para ambas, citam como possível causa para a dificuldade em cumprir o planejamento: “[...] 
são feriados, eventos, greves, problemas na escola, falta de material, falta de investimentos... E isso é comum em outras escolas também" (PROFESSORA B). Ambas as professoras relataram que poucas instituições de ensino apresentam estruturas como laboratório de informática ou multidisciplinar.

Quando vamos as vozes dos discentes, ao serem perguntados sobre seus objetivos e perspectivas quanto ao seu estudo no Ensino Médio, os alunos relataram ter foco em: obter aprovação em universidades públicas ou cursos técnicos (dois alunos) e na busca de emprego (dois alunos). Em resposta à pergunta um dos alunos informou: "Eu quero melhorar de vida, ajudar minha família e preciso de um bom emprego, aí tem que estudar né?" (ALUNO A).

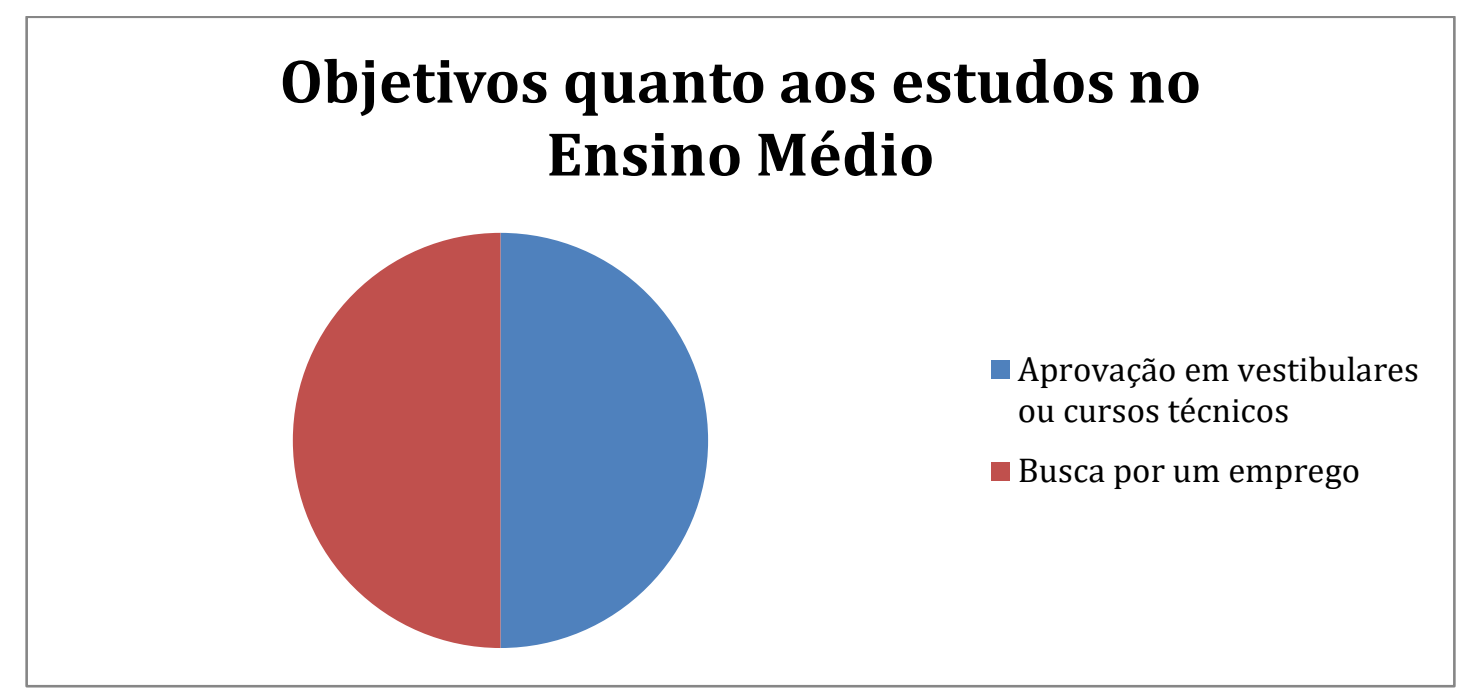

Ao serem perguntadas sobre os conhecimentos ministrados em sala de aula as professoras relataram que é difícil a relação com a realidade dos alunos, os conteúdos são descontextualizados. Uma delas afirmou: "São trabalhados conteúdos engessados, pouco voltados ao cotidiano dos alunos, ao que eles vivem” (PROFESSORA C). Ou seja, os conteúdos estão sendo desenvolvido sem atender ao contexto histórico, social e econômico do público ao qual se aplica, deixando de atender às reais necessidades dos estudantes. Se torna difícil para os alunos perceberem a aplicação desses assuntos estudados em sala de aula, visualizar sua origem e relevância assim como seu aprofundamento para melhor qualificação e êxito na busca de seus objetivos. Tanto que ao serem perguntados sobre a relação dos conteúdos abordados em sala de aula com sua realidade, os alunos entrevistados pouco souberam relatar, um dos relatos foi: "Procuro aprender os assuntos para conseguir passar nas provas, passar de ano e no vestibular" 
(ALUNO B). Outro aluno relatou: "Não sei pra que estudamos certos assuntos, não serve pra nada... Só uso na sala mesmo" (ALUNO C).

Como proposta de melhora tanto os alunos quanto as professoras abordaram em suas respostas a necessidade de melhorar a estrutura das escolas, as professoras enfatizaram as melhorias nas escolas do campo, as quais estão prejudicadas em sua grande maioria. As educadoras também afirmaram sobre a necessidade de maior contextualização dos conteúdos. Além da melhor capacitação dos professores para ampliar o acesso ao ensino, com ênfase para a educação especial.

\section{CONSIDERAÇÕES POSSÍVEIS}

Um grande desafio colocado sobre a educação consiste na necessidade de um serviço público que garanta o direito à educação e acesso à cultura para todas as crianças e jovens, com igualdade e mesmas oportunidades de justiça social. Na visão de Barroso (2005), é relevante desmontar a lógica de mercado na educação, fazendo da regulação e construção das políticas educativas um processo de construção coletiva, em condições de igualdade para todos os cidadãos.

Segundo Sposito e Carrano (2003) outro desafio é colocar as políticas de juventude em uma pauta ampliada de direitos públicos de caráter universalista. Considerando os jovens sujeitos com autonomia e personagens ativos no processo de formulação, execução e avaliação das políticas a eles destinadas.

De acordo com Carmo (2013), uma proposta encontrada nos Parâmetros Curriculares Nacionais do Ensino Médio, visa à aproximação da escola à nova realidade nacional. Propondo aos jovens e adolescentes uma participação social mais ativa.

Talvez uma administração formada por uma concepção crítica de Estado, veja como seu real objetivo e função atender a sociedade como um todo, não favorecendo apenas aos grupos detentores de poder econômico, mas tendo como prioridade programas de ação universalizantes, incorporando conquistas sociais pelos grupos e setores desfavorecidos, no intuito de propor um equilíbrio social.

A partir das entrevistas realizadas foi possível identificar que os alunos vêm tendo dificuldades em relacionar os conteúdos abordados em sala de aula com a realidade em que vivem, chegando a ter esses assuntos apenas como necessários para aprovação em processos avaliativos, pouco visualizando sua interação com o contexto em que se vive. Sobre os objetivos e perspectivas dos alunos acerca do Ensino Médio foi possível 
perceber a busca por um emprego, vaga em universidades ou cursos técnicos, vendo o Ensino Médio como uma etapa para cumprir e se alcançar um desses objetivos. Pouco foi observado sobre a relação com o saber, a motivação pela busca do conhecimento e compreensão da realidade.

Na visão das professoras são identificados três perfis de escolas no município de Abaetetuba, as que buscam apenas aprovação em vestibulares, as que visam, além disso, o trato de conhecimentos culturais e as que apenas se preocupam em transmitir conteúdos em sua maioria descontextualizados. Pouco se tem feito a relação com o conhecimento e com a realidade vivida pelos alunos, não favorecendo sua compreensão da mesma. Também foi mencionada a falta de investimentos em infraestrutura, preparação e desenvolvimento das escolas, principalmente de educação no campo e sobre a educação especial as quais tem apresentado ainda mais necessidades nesse contexto.

É central o trato de conteúdos contextualizados, voltados à realidade em que o sujeito vive, os conhecimentos escolares e científicos são importantes e devem ser abordados, certamente, porém é interessante a relação dos mesmos com o contexto social, político, econômico e cultural em que o aluno vive, para assim lhe oferecer condições de compreender tais realidades e poder atuar sobre elas. É visível também a necessidade de maiores investimentos sobre a educação em termos de infraestrutura, acessibilidade e garantia de direitos, abordados inclusive, nas leis.

Até mesmo quando se fala na busca por um bom emprego ou na preparação para aprovação em vestibulares ou cursos técnicos, parcela significativa dos alunos do ensino Médio é obrigada a recorrer a cursos para além de sua escola pública, como cursinhos preparatórios. Por não estar conseguindo alcançar seu objetivo apenas na escola pública.

Sabendo que a educação é central para o desenvolvimento social e expansão de uma dada região, durante esse processo educativo é interessante o diálogo e a relação com instituições ligadas ao ensino e à extensão, para que assim possa haver uma maior aproximação do ensino à realidade do jovem, podendo tornar a escola mais estimulante, assegurando os direitos à liberdade ao respeito e às identidades. Fazendo uma reflexão sobre a realidade atual é perceptível a necessidade de políticas que preparem os alunos para a cidadania, possibilitando a compreensão do contexto social, político e econômico em que se encontram. 


\section{REFERÊNCIAS}

BARROSO, João. O Estado, a Educação e a Regulação das Políticas Públicas.

Educ. Soc., Campinas, vol. 26, n. 92, p. 725-751, Especial - Out. 2005. Disponível em, http://www.cedes.unicamp.br. Acesso em, 20/12/2018.

CARMO, Erinaldo Ferreira. Et al. Desafios do Ensino Médio e Políticas Públicas Educacionais. Divers@ Revista Eletrônica Interdisciplinar. Matinhos. Vol.6, n.1, p.177. 2013. Disponível em, revistas.ufpr.br. Acesso em, 20/12/2018.

DOURADO, Luiz Fernandes. Plano Nacional de Educação: o epicentro das políticas de estado para a educação brasileira. Goiania: Editora da Imprensa Universitária. ANPAE, 2017.

Educação Básica 2014. Disponível em, https://atlasescolar.ibge.gov.br/images/atlas/mapas_brasil/brasil_educacao_basica.pdf. Acesso em 24/12/2018.

GRAMSCI, Antônio Cadernos do Cárcere v2 Os Intelectuais; O Princípio Educativo; Jornalismo. $4^{\text {a }}$ ed: Rio de Janeiro: 2006

HOFLING, Eliosa da Mattos. Estado e Políticas (Pública) Sociais. Cedes, ano XXI, $\mathrm{n}^{\circ}$ 55, novembro/2001. Disponível em, WWW.scielo.br. Acesso em 16/11/2018.

LIMA. Cláudia R. et al. Políticas Públicas Educacionais Brasileiras: O Ensino Médio no Contexto da LDB, PNE e PDE. PUCPR. 2009. Disponível em, educere.bruc.com.br. Acesso em, 23/12/2018.

MELO, Savana Diniz Gomes. DUARTE, Adriana. Políticas para o Ensino Médio no Brasil: Perspectivas para a Universalização.Cad. Cedes, Campinas, vol. 31, n. 84, p. 231-251, maio-ago. 2011. Disponível em http://www.cedes.unicamp.br. Acesso em, $24 / 12 / 2018$.

Plano de Desenvolvimento da Escola - PDE-Escola. Disponível em, http://portal.mec.gov.br/component/content/article/137-programas-e-acoes 1921564125/pde-plano-de-desenvolvimento-da-educacao-102000926/176-apresentacao. Acesso em 24/12/2018.

PEREIRA, Ricardo Augusto Gomes. Ensino Médio Integrado como Política Pública: Implicações ao Desenvolvimento do Ensino Médio no Estado do Pará. 2008.

Disponível em, WWW.cee.pa.gov.br. Acesso em, 24/12/2018.

PNE. Disponível em, http://pne.mec.gov.br/18-planos-subnacionais-de-educacao/543plano-nacional-de-educacao-lei-n-13-005-2014. Acesso em 24/12/2018

SIMÕES, Carlos Artexes. Iniciativas governamentais e o Ensino Médio Inovador.RevistaRetratos da Escola, Brasília, v. 5, n. 8, p. 111-125, jan./jun. 2011. Disponível em: <http//www.esforce.org.br>. Acesso em, 20/12/18. 
SPOSITO, Marília Pontes. CARRANO, Paulo César Rodrigues. Juventude e Políticas Públicas no Brasil. Universidade Federal Fluminense, Faculdade de Educação Observatório Jovem do Rio de Janeiro Set /Out /Nov /Dez 2003 N. 24. Disponível em,WWW.scielo.br. Acesso em, 16/12/2018

Recebido em: 20/01/2022

Aprovado em: 21/02/2022

Publicado em: 25/02/2022 